\title{
Microwave-assisted synthesis of (aminomethylene)bisphos- phine oxides and (aminomethylene)bisphosphonates by a three-component condensation
}

\author{
Erika Bálint ${ }^{*}{ }^{1}$, Ádám Tajti ${ }^{2}$, Anna Dzielak ${ }^{2}$, Gerhard Hägele ${ }^{3}$ and György Keglevich ${ }^{* 2}$
}

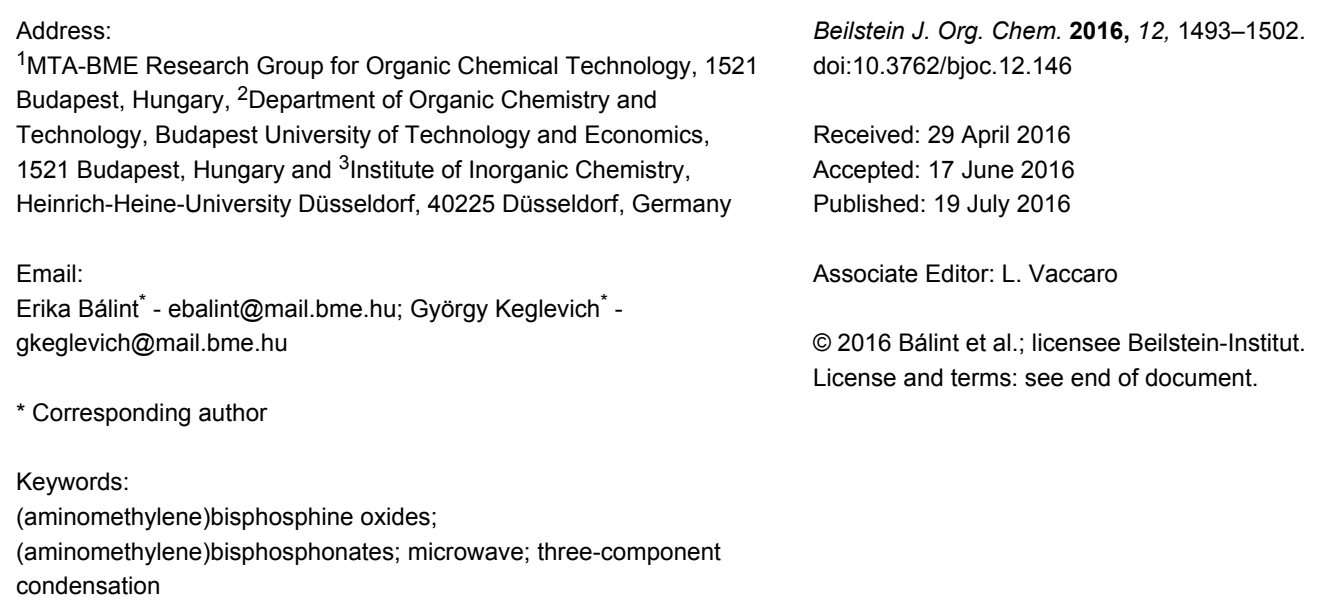

\section{Abstract}

A practical method was elaborated for the synthesis of (aminomethylene)bisphosphine oxides comprising the catalyst- and solventfree microwave-assisted three-component condensation of primary amines, triethyl orthoformate and two equivalents of diphenylphosphine oxide. The method is also suitable for the preparation of (aminomethylene)bisphosphonates using $(\mathrm{MeO})_{2} \mathrm{P}(\mathrm{O}) \mathrm{H} /(\mathrm{MeO})_{3} \mathrm{CH}$ or $(\mathrm{EtO})_{2} \mathrm{P}(\mathrm{O}) \mathrm{H} /(\mathrm{EtO})_{3} \mathrm{CH}$ reactant pairs and even secondary amines. Several intermediates referring to the reaction mechanism together with a few by-products could also be identified.

\section{Introduction}

Substituted (hydroxymethylene)bisphosphonic acid derivatives form an important group of drugs used in the treatment of osteoporosis and related bone diseases [1-3]. In the last decades, at least three generations of dronic acid derivatives appeared [4].

(Aminomethylene)bisphosphonic acid derivatives are analogous species, that also have potential bioactivity in bone diseases, besides they display antibacterial, antiparasitic, anticancer and herbicidal activities [5].

(Aminomethylene)bisphosphonates may be prepared in different ways [5]. One of the most convenient and widespread methods is the three-component condensation involving an amine, an orthoformate and a dialkyl phosphite. Usually, primary or secondary amines were reacted with an equivalent, 
or a small excess of triethyl orthoformate and 2-7 equivalents of diethyl phosphite [6-21]. In most cases, the corresponding acids were the target molecules that were obtained by hydrolysis of the esters [15-21]. The use of crown ethers with an $\mathrm{NH}$ unit, or thienopyrimidine amines as starting materials was also reported $[22,23]$. The catalyst- and solvent-free methods required long reaction times and/or a high temperature [6-14,2123]. Ionic liquids and a few catalysts were also tried out [2427], and the synthesis was also described under microwave (MW) irradiation [28-32]. However, most of the MW-assisted syntheses were performed in kitchen ovens [28-30], hence these results cannot be reproduced.

The mechanism of the three-component condensation has been investigated by the research group of Krutikov and Kafarski [6,7]. A detailed proposal is shown in Scheme 1 [7]. The first step of the condensation is the reaction of the amine with the

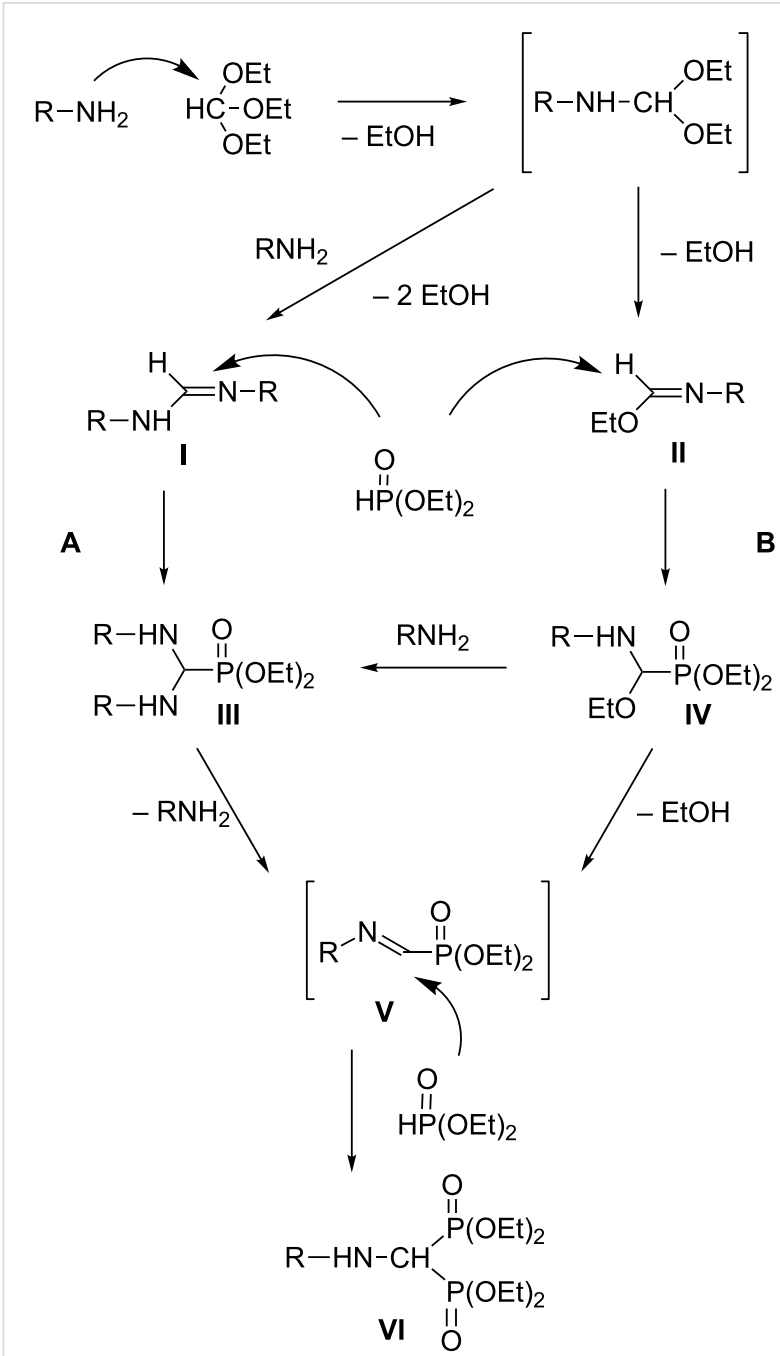

Scheme 1: Proposed routes for the three-component condensation [7]. orthoformate, in which imine-type intermediates I or II may be formed. The next step is the nucleophilic addition of diethyl phosphite to the $\mathrm{C}=\mathrm{N}$ bond of the imines resulting in phosphonates III or IV, respectively. Then, the elimination of an amine or ethanol and the addition of another unit of diethyl phosphite may lead to (aminomethylene)bisphosphonates (VI). If the amine is in predominance over the phosphite in the reaction, the pathway $\mathbf{A}$ is more likely, but if the phosphite is used in excess, the pathway $\mathbf{B}$ comes to the fore.

There are other possibilities to synthesize (aminomethylene)bisphosphonates, such as by the reaction of dimethylformamide diethyl acetal with diethyl phosphite (Scheme 2a) [33], by the condensation of formamides and diethyl phosphite using 2,6-ditert-butyl-4-methylpyridine (DTBMP) as the base, and trifluoromethanesulfonic anhydride $\left(\mathrm{Tf}_{2} \mathrm{O}\right)$ as the catalyst (Scheme 2b) [34], or by the reaction of isonitriles with triethyl phosphite (Scheme 2c) [35,36]. (Aminomethylene)bisphosphonates can also be obtained starting from amides, triethyl phosphite and phosphorus oxychloride (Scheme 3a) [37], or in the reaction of amines with diazophosphonate in the presence of a rhodium catalyst (Scheme 3b) [38].

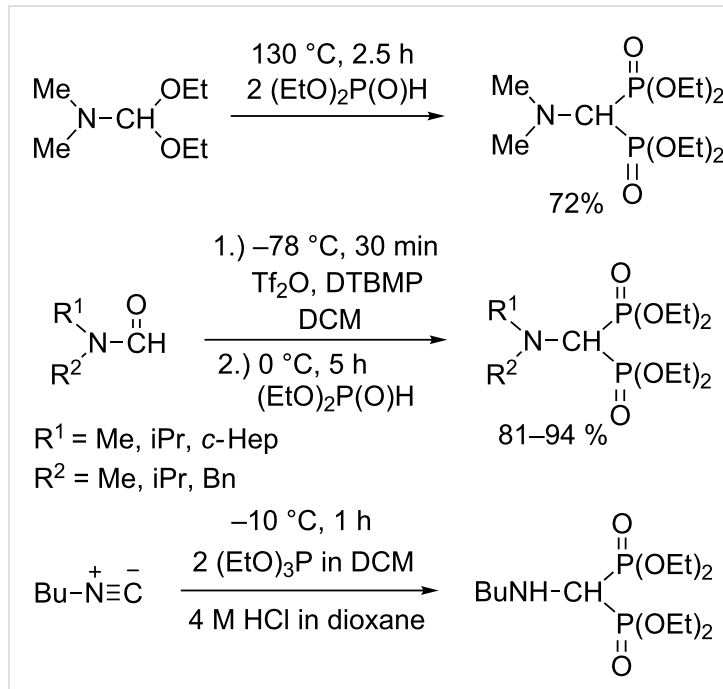

Scheme 2: Synthetic methods for (aminomethylene)bisphosphonates I.

(Aminomethylene)bisphosphine oxides are analogous to (aminomethylene)bisphosphonates, but they are much less studied. Only a few publications were found, which focus on their synthesis [33,39-42], however, a three-component condensation has not been described. They can also be prepared starting from dimethylformamide dimethyl acetal, as in the synthesis of (aminomethylene)bisphosphonates, but in the latter case a secondary phosphine oxide is the P-reagent [33,39]. In addition, (aminomethylene)bisphosphine oxides can be synthe- 


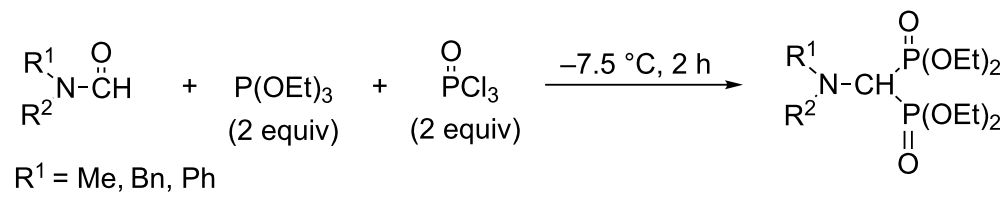

$$
\begin{aligned}
& \mathrm{R}^{2}=\mathrm{H}, \mathrm{Me} \\
& \text { 30-78\% }
\end{aligned}
$$

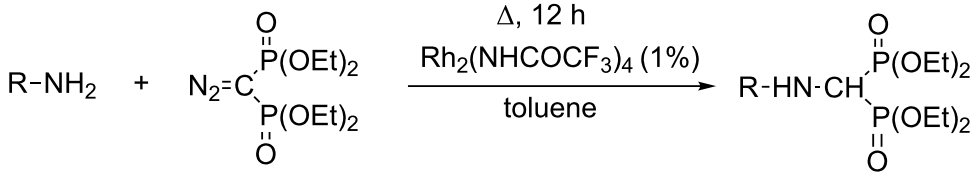

$$
\begin{aligned}
& \mathrm{R}=\mathrm{Ph}, 4-\mathrm{MeO}-\mathrm{Ph}, 4-\mathrm{NO}_{2}-\mathrm{Ph} \quad 76-87 \%
\end{aligned}
$$

Scheme 3: Synthetic methods for (aminomethylene)bisphosphonates II.

sized by the reaction of two molecules of (dialkylamino)(diphenylphosphinoyl)chloromethane (Scheme 4a) [40,41], or by the addition of diphenylphosphine oxide to an isonitrile (Scheme 4b) [36,42].

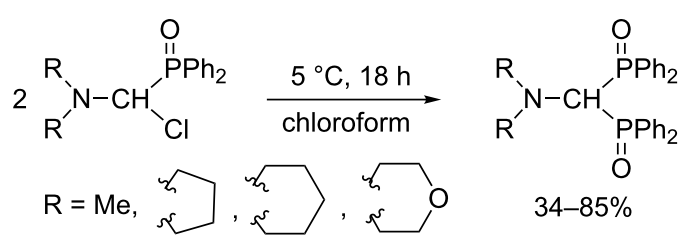

$80^{\circ} \mathrm{C}, 4$ days

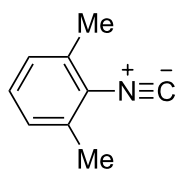
$\mathrm{Rh}(\operatorname{cod})_{2} \mathrm{Cl}_{2}(5 \%)$

$\frac{2 \mathrm{Ph}_{2} \mathrm{P}(\mathrm{O}) \mathrm{H}}{\text { toluene }}$

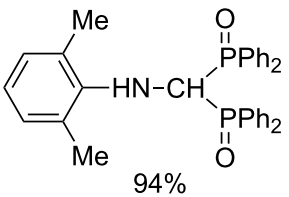

Scheme 4: Synthetic methods for (aminomethylene)bisphosphine oxides.

In this paper, we wish to report the results of our investigations on the synthetic protocol utilizing the three-component condensations of primary or secondary amines, orthoformates and $>\mathrm{P}(\mathrm{O}) \mathrm{H}$ species, such as dialkyl phosphites or diphenylphos- phine oxide, and we aimed at the preparation of new derivatives.

\section{Results and Discussion}

\section{Synthesis of alkylamino- and (phenylamino-} methylene)bisphosphine oxides

In the first series of experiments, the condensation of primary amines, such as butyl-, cyclohexyl- and benzylamine or aniline with triethyl orthoformate, and 2 equivalents of diphenylphosphine oxide at $150{ }^{\circ} \mathrm{C}$ for $1 \mathrm{~h}$ under MW conditions was studied (Scheme 5). To avoid the formation of by-products, benzylamine was reacted at a lower temperature of $125^{\circ} \mathrm{C}$ (Table 1 , entry 3$)$. The reactions were carried out without any catalyst and solvent. After column chromatography, the new aminomethylenebisphosphine oxides $\mathbf{1 a - d}$ were obtained in yields of $72-82 \%$ (Table 1 , entries $1-4)$.

$\begin{aligned} & \text { Table 1: Synthesis of alkylamino- and (phenylaminomethylene)bispho- } \\
& \text { sphine oxides 1a-d. }\end{aligned}$
\begin{tabular}{cccc} 
Entry & $\mathrm{Y}$ & $T\left({ }^{\circ} \mathrm{C}\right)$ & Yield (\%) \\
\hline 1 & $\mathrm{Bu}$ & 150 & $82(\mathbf{1 a})$ \\
2 & $\mathrm{C}-\mathrm{Hex}$ & 150 & $79(\mathbf{1 b})$ \\
3 & $\mathrm{Bn}$ & $125^{\mathrm{b}}$ & $72(\mathbf{1 c})$ \\
4 & $\mathrm{Ph}$ & 150 & $80(\mathbf{1 d})$
\end{tabular}

alsolated yield. ${ }^{\mathrm{b}}$ At $150{ }^{\circ} \mathrm{C}$ by-products were formed.

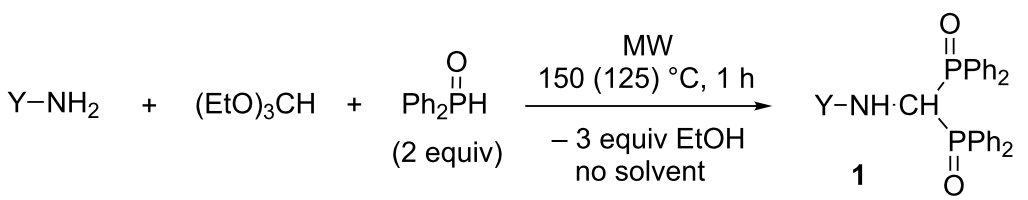

$$
\begin{aligned}
& \mathrm{Y}=\mathrm{Bu}(\mathbf{a}), \mathrm{c}-\mathrm{Hex}(\mathbf{b}), \mathrm{Bn}(\mathbf{c}), \mathrm{Ph}(\mathbf{d})
\end{aligned}
$$


The condensation of simple secondary amines (diethyl-, dibutyl-, $\mathrm{N}$-butylmethyl-, $\mathrm{N}$-cyclohexylmethyl-, $\mathrm{N}$-benzylmethylamine, $N$-methylaniline and morpholine) was also investigated with triethyl orthoformate, and 2 equivalents of diphenylphosphine oxide (Scheme 6, Table 2). The $\mathrm{MW}$-assisted reactions were performed at $150^{\circ} \mathrm{C}$ for $1 \mathrm{~h}$ under solvent- and catalyst-free conditions, and the (dialkyl-amino-

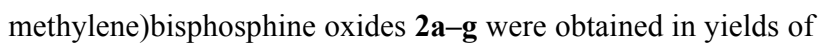
60-85\% after column chromatography (Table 2, entries 1-7). Except for compound 2g, all (aminomethylene)bisphosphine oxides $(\mathbf{2} \mathbf{a}-\mathbf{f})$ prepared are new compounds. According to the literature method [41], $\mathbf{2 g}$ was synthesized by the reaction of two molecules of (diphenylphosphinoyl)morpholinochloromethane in the presence of chloroform at $5{ }^{\circ} \mathrm{C}$ for $18 \mathrm{~h}$ in a yield of $41 \%$ (Scheme $4 \mathrm{a}$ ). Using the MW-assisted threecomponent condensation method, this compound $(\mathbf{2 g})$ can be synthesized without any catalyst and solvent in a short time $(1 \mathrm{~h})$, and in a yield of $85 \%$ (Table 2 , entry 7 ).

\begin{tabular}{|c|c|c|c|}
\hline Entry & $Y^{1}$ & $\mathrm{Y}^{2}$ & Yield $(\%)^{a}$ \\
\hline 1 & Et & Et & $82(2 a)$ \\
\hline 2 & $\mathrm{Bu}$ & $\mathrm{Bu}$ & $73(\mathbf{2 b})$ \\
\hline 3 & $\mathrm{Bu}$ & $\mathrm{Me}$ & $69(2 c)$ \\
\hline 4 & c-Hex & $\mathrm{Me}$ & $66(2 d)$ \\
\hline 5 & $\mathrm{Bn}$ & $\mathrm{Me}$ & $64(2 e)$ \\
\hline 6 & $\mathrm{Ph}$ & $\mathrm{Me}$ & $60(\mathbf{2 f})$ \\
\hline 7 & \multicolumn{2}{|c|}{$-\left(\mathrm{CH}_{2}\right)_{2}-\mathrm{O}-\left(\mathrm{CH}_{2}\right)_{2}^{-}$} & $85(2 g)$ \\
\hline
\end{tabular}

alsolated yield.

\section{Synthesis of alkylamino- and (phenylamino- methylene)bisphosphonates}

In the next stage, our method was extended to the synthesis of alkyl- and (phenylaminomethylene)bisphosphonates by reacting butyl- and cyclohexylamine or aniline, and triethyl orthoformate with diethyl phosphite under MW irradiation in the absence of catalyst and solvent (Table 3). First, the condensa- tion of butylamine, triethyl orthoformate with 2 equivalents of diethyl phosphite was studied at $125{ }^{\circ} \mathrm{C}$. After a 2 h's reaction time, the conversion was $91 \%$, and beside the expected (aminomethylene)bisphosphonate 3a formed in $81 \%$, the $N$-ethylated by-product 4 a was formed in $19 \%$ (Table 3, entry 1). Increasing the temperature to $150{ }^{\circ} \mathrm{C}$, the reaction was completed after $30 \mathrm{~min}$, but the proportion of the main product 3a was somewhat lower (78\%), and another by-product 5a also appeared in $7 \%$ (Table 3, entry 2). The target compound 3a could be obtained in a yield of $61 \%$. Using 3.5 equivalents of diethyl phosphite at $125{ }^{\circ} \mathrm{C}$ for $1 \mathrm{~h}$, the conversion was only $75 \%$, but the expected product $\mathbf{3 a}$ was formed exclusively (Table 3, entry 3). After a longer reaction time of $1.5 \mathrm{~h}$, by-product $4 \mathbf{a}$ also appeared in $22 \%$ (Table 3 , entry 4 ). In the reaction with cyclohexylamine, the same tendency was observed (Table 3, entries 5-8), and the corresponding (cyclohexylaminomethylene)bisphosphonate $\mathbf{3} \mathbf{b}$ was obtained in a yield of $68 \%$ after column chromatography (Table 3, entry 6). Finally, the three-component condensation of aniline, triethyl orthoformate and diethyl phosphite was studied (Table 3, entries 9-11). Applying 2 equivalents of phosphite, the reaction was not complete, neither at $125{ }^{\circ} \mathrm{C}$, nor at $150{ }^{\circ} \mathrm{C}$ (Table 3 , entries 9 and 10). Two types of imine intermediates (6a and $\mathbf{6 b}$ ) could be observed in the reaction mixture beside the expected product 3c. These intermediates refer to the mechanism of the condensation (see compounds $\mathbf{I}$ and $\mathbf{V}$ in Scheme 1, pathway A). Previously, iminephosphonate $\mathbf{6 b}$ was only an assumed intermediate [7], but now we could prove it by ${ }^{31} \mathrm{P}$ NMR and HRMS (Table 4). Increasing the amount of diethyl phosphite to 3 equivalents, the reaction was complete at $125^{\circ} \mathrm{C}$ after $1 \mathrm{~h}$, and only $3 \mathbf{c}$ was formed with a yield of $82 \%$ (Table 3 , entry 11 ). In the cases discussed, no ethylated or formylated by-products ( 4 and $\mathbf{5}$, respectively) were formed. (Aminomethylene)bisphosphonates $\mathbf{3 b}$ and $\mathbf{3 c}$ were synthesized earlier in unoptimized experiments to provide compounds $\mathbf{3 b}$ and $\mathbf{3 c}$ in yields of $36 \%$ [9] and $53 \%$ [8], respectively. The former compound $\mathbf{3 b}$ was characterized only by ${ }^{1} \mathrm{H}$ NMR [9]. Compound $\mathbf{3 c}$ was also synthesized under MW irradiation in a yield of $75 \%$ [31]. It can be seen, that the refined MW-assisted method elaborated by us

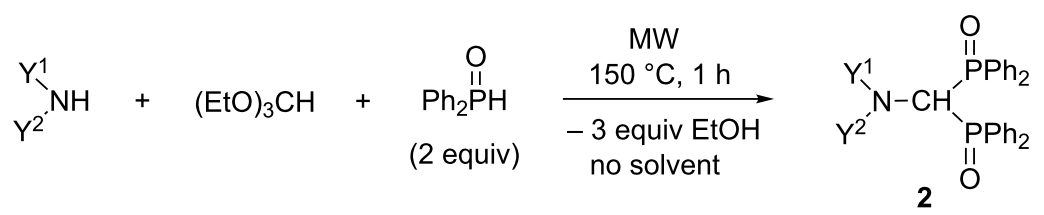

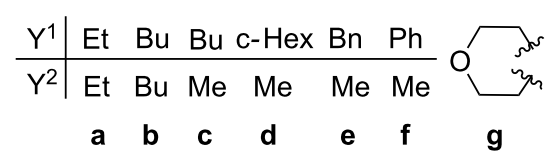


Table 3: The reactions of primary amines with triethyl orthoformate and diethyl phosphite.

\begin{tabular}{|c|c|c|c|c|c|c|c|c|c|}
\hline \multirow{4}{*}{ Entry } & \multirow{4}{*}{$Y$} & \multirow{4}{*}{$\begin{array}{r}\text { Y-NH } \\
\\
\\
\begin{array}{c}\text { DEP } \\
\text { (equiv) }\end{array}\end{array}$} & \multirow{4}{*}{$T\left({ }^{\circ} \mathrm{C}\right)$} & \multirow{4}{*}{$\begin{array}{l}\stackrel{O}{I 1}_{2}^{\mathrm{PH}} \\
t(\mathrm{~h})\end{array}$} & $\begin{array}{c}\text { MW } \\
T, t \\
-3 \text { equiv EtOH } \\
\text { no solvent }\end{array}$ & 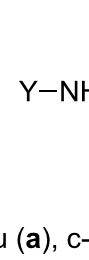 & \multicolumn{2}{|c|}{$\begin{array}{l}\mathrm{O}_{\mathrm{P}} \mathrm{P}(\mathrm{OEt})_{2} \\
\mathrm{P}_{\mathrm{O}}^{\mathrm{P}}(\mathrm{OEt})_{2} \\
\text { b), } \mathrm{Ph}(\mathbf{c})\end{array}$} & \multirow{4}{*}{$\begin{array}{c} \\
\\
\begin{array}{c}\text { Yield of } 3 \\
(\%)^{c}\end{array}\end{array}$} \\
\hline & & & & & \multirow{3}{*}{$\begin{array}{c}\text { Conversion } \\
(\%)^{\mathrm{a}}\end{array}$} & \multicolumn{3}{|c|}{ Product composition (\%) ${ }^{a}$} & \\
\hline & & & & & & \multirow[t]{2}{*}{3} & \multicolumn{2}{|c|}{ by-products ${ }^{b}$} & \\
\hline & & & & & & & 4 & 5 & \\
\hline 1 & $\mathrm{Bu}$ & 2 & 125 & 2 & 91 & 81 & 19 & 0 & - \\
\hline 2 & $\mathrm{Bu}$ & 2 & 150 & 0.5 & 100 & 78 & 15 & 7 & $61(3 a)$ \\
\hline 3 & $\mathrm{Bu}$ & 3.5 & 125 & 1 & 75 & 100 & 0 & 0 & - \\
\hline 4 & $\mathrm{Bu}$ & 3.5 & 125 & 1.5 & 90 & 78 & 22 & 0 & - \\
\hline 5 & c-Hex & 2 & 125 & 2 & 76 & 83 & 17 & 0 & - \\
\hline 6 & c-Hex & 2 & 150 & 0.5 & 100 & 88 & 10 & 2 & $68(3 b)$ \\
\hline 7 & c-Hex & 3.5 & 125 & 1 & 63 & 100 & 0 & 0 & - \\
\hline 8 & c-Hex & 3.5 & 125 & 1.5 & 83 & 86 & 14 & 0 & - \\
\hline 9 & $\mathrm{Ph}$ & 2 & 125 & 2 & 68 & $56^{d}$ & 0 & 0 & $36(3 c)$ \\
\hline 10 & $\mathrm{Ph}$ & 2 & 150 & 1 & 90 & $70^{d}$ & 0 & 0 & $52(3 c)$ \\
\hline 11 & $\mathrm{Ph}$ & 3 & 125 & 1 & 100 & 100 & 0 & 0 & $82(3 c)$ \\
\hline
\end{tabular}

aOn the basis of GC (entries 1-8) or on the basis of HPLC (entries 9-11). bThe by-products identified:<smiles>[R]N(C=[R20])[C@H](N([R])C=O)[P+](=O)OCC</smiles>

$\mathrm{R}=\mathrm{Bu}(\mathbf{a}), \mathrm{c}-\mathrm{Hex}(\mathbf{b})$

CIsolated yield. ${ }^{\mathrm{d}}$ The following intermediates were also formed based on LC-MS:

$\lceil-\mathrm{N}=\mathrm{CH}-\mathrm{NH}-\square$

6 a<smiles>CCO[PH3+](=O)C=Nc1ccccc1</smiles>

$6 b$

\begin{tabular}{c|crc} 
Entry & $\mathbf{6 a}$ & {$[\%]$} & $\mathbf{6 b}$ \\
\hline $\mathbf{9}$ & 29 & 15 \\
10 & 18 & 12
\end{tabular}

Table 4: Spectral characterization of $\mathrm{N}$-ethyl- (4) and $\mathrm{N}$-formyl- (5) (aminomethylene)bisphosphonates and imine-type intermediates 6a and 6b.

\begin{tabular}{|c|c|c|c|c|}
\hline Compounds & $\delta_{\mathrm{P}}$ in $\mathrm{CDCl}_{3}$ & $\delta_{P}[$ lit.] & {$[\mathrm{M}+\mathrm{H}]^{+}$found } & {$[\mathrm{M}+\mathrm{H}]^{+}$requires } \\
\hline $4 a$ & 19.98 & - & 388.2020 & 388.2012 \\
\hline $4 b$ & 20.63 & - & 414.2162 & 414.2169 \\
\hline $5 a$ & $\begin{array}{l}16.08 \text { and } 16.16 \\
(E \text { and } Z \text { isomers) }\end{array}$ & $\begin{array}{c}15.69 \text { and } 15.98^{a} \\
(E \text { and } Z \text { isomers) [43] }\end{array}$ & 388.1659 & 388.1649 \\
\hline $5 b$ & $\begin{array}{l}16.00 \text { and } 16.06 \\
(E \text { and } Z \text { isomers) }\end{array}$ & - & 414.1797 & 414.1805 \\
\hline $6 a$ & - & - & 197.1075 & 197.1073 \\
\hline $6 b$ & 17.67 & - & 242.0936 & 242.0941 \\
\hline
\end{tabular}

a $\mathrm{CCl}_{4}$ 
may give the (aminomethylene)bisphosphonates $\mathbf{3 b}$ and $\mathbf{3 c}$ in yields of $68 \%$ and $82 \%$, respectively.

Next, the condensation of aniline with trimethyl orthoformate and dimethyl phosphite was also performed (Scheme 7). In this case, the reaction was complete after a $1 \mathrm{~h}$ heating at $110{ }^{\circ} \mathrm{C}$ using 3.5 equivalents of dimethyl phosphite. After column chromatography, the corresponding product $7 \mathbf{a}$ was isolated in a yield of $63 \%$. At higher temperatures, decomposition was observed.

In the next stage, the MW-assisted reaction of secondary amines was studied with triethyl orthoformate and diethyl phosphite (Scheme 8). The condensations were carried out applying 3.5 equivalents of diethyl phosphite at $125^{\circ} \mathrm{C}$ for $1 \mathrm{~h}$ in the absence of a catalyst and a solvent. In case of $N$-methylaniline, 4.5 equivalents of the P-reagent was necessary to attain complete conversion (Table 5, entry 6 ). The corresponding (dialkylaminomethylene)bisphosphonates $(\mathbf{8 a}-\mathbf{g})$ were obtained in yields of $65-86 \%$ after purification by chromatography (Table 5, entries 1-7).

Finally, the three-component condensation of aniline, triethyl orthoformate and dimethyl or dibutyl phosphite was studied (Table 6, Figure 1). Using dimethyl phosphite, the reactions were performed at $110^{\circ} \mathrm{C}$ for $1 \mathrm{~h}$, but in case of dibutyl phosphite, the conditions applied were the same as those in the condensations with diethyl phosphite $\left(125-150{ }^{\circ} \mathrm{C}, 1 \mathrm{~h}\right)$. Using 2 equivalents of dialkyl phosphite, more or less transesterified

\begin{tabular}{|cccc}
\hline \multicolumn{4}{|c}{ Table 5: Synthesis of (dialkylaminomethylene)bisphosphonates 8a-g. } \\
\hline Entry & $\mathrm{Y}^{1}$ & $\mathrm{Y}^{2}$ & Yield (\%) $^{\mathrm{a}}$ \\
\hline 1 & $\mathrm{Et}$ & $\mathrm{Et}$ & $86(\mathbf{8 a})$ \\
2 & $\mathrm{Bu}$ & $\mathrm{Bu}$ & $68(\mathbf{8 b})$ \\
3 & $\mathrm{Bu}$ & $\mathrm{Me}$ & $79(\mathbf{8 c})$ \\
4 & $\mathrm{C}-\mathrm{Hex}$ & $\mathrm{Me}$ & $72(\mathbf{8 d})$ \\
5 & $\mathrm{Bn}$ & $\mathrm{Me}$ & $70(\mathbf{8 e})^{\mathrm{b}}$ \\
$6^{\mathrm{c}}$ & $\mathrm{Ph}$ & $\mathrm{Me}$ & $65(\mathbf{8 f})$ \\
7 & $-\left(\mathrm{CH}_{2}\right)_{2}-\mathrm{O}-\left(\mathrm{CH}_{2}\right)_{2}$ & $81(\mathbf{8 g})^{\mathrm{d}}$ \\
\hline
\end{tabular}

alsolated yield. ${ }^{b}$ It was synthesized in a yield of $61 \%$ [10]. ${ }^{c} 4.5$ equivalents of diethyl phosphonate was used. ${ }^{\text {IIt }}$ was synthesized in a yield of $46 \%[4]$.

(aminomethylene)bisphosphonates (9-11 and 3c) were also formed beside the expected (phenylaminomethylene)bisphosphonates $7 \mathbf{a}$ or $7 \mathbf{b}$ (Table 6 ,entries 1 and 6,7 ). The transesterified by-products (9-11 and 3c) were indentified by GC-MS (Figure 2) or LC-MS, and were proved by HRMS (Table 7). The composition of the reaction mixture for the experiment marked by Table 6 , entry 6 was analyzed by ${ }^{31} \mathrm{P}$ NMR (see Figure 3). It was observed that increasing the quantity of dialkyl phosphite, the proportion of the by-products was decreased, and the condensations became more selective for the desired product (7a or $7 \mathbf{b}$ ) (Table 6 , Figure 1 ). In the reaction with dimethyl phosphite, the best result was achieved using 20 equivalents of the P-reagent, but in case of dibutyl phosphite, a 15 -fold excess was sufficient (Table 6 , entries 5 and 10).

S: Synthesis of tetramethyl (phenylaminomethylene)bisphosphonate.

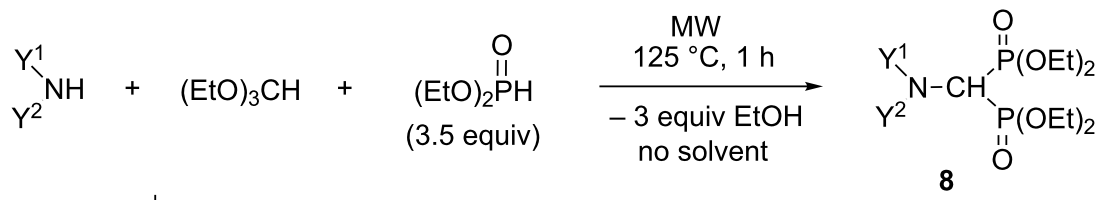

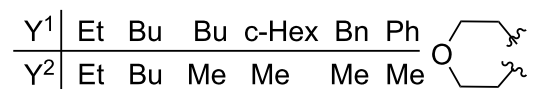

$$
\begin{aligned}
& \begin{array}{llllllll}
a & b & c & d & e & f & & g
\end{array}
\end{aligned}
$$


Table 6: Condensation of aniline, triethyl orthoformate and dimethyl or dibutyl phosphite.
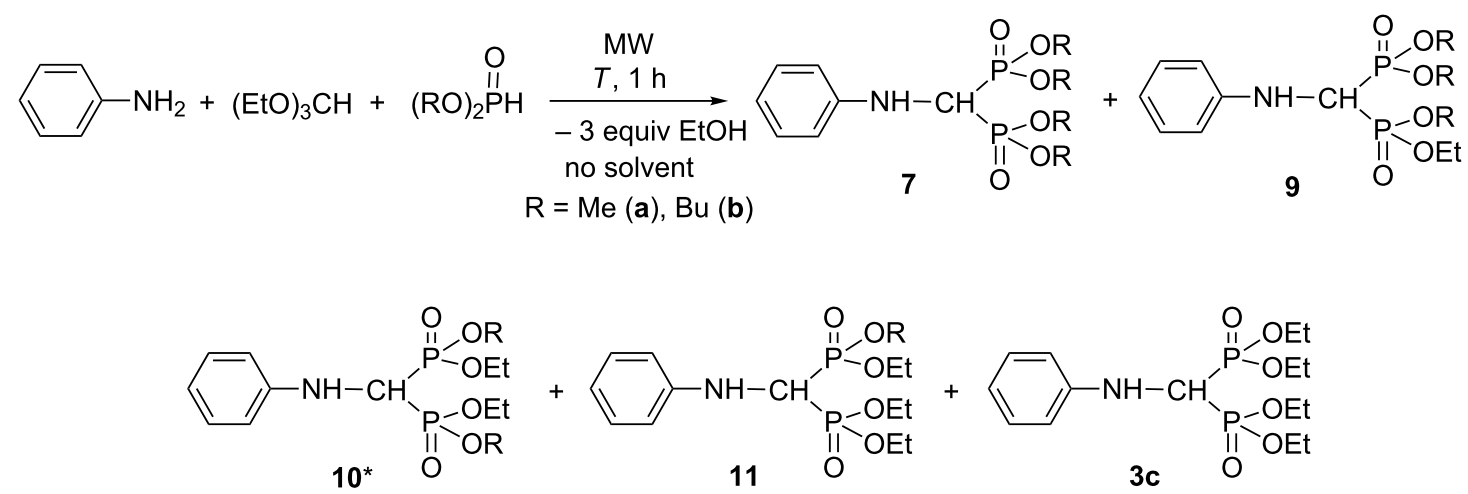

*tentative assignment

\begin{tabular}{ccccccccc}
\hline Entry & $\mathrm{R}$ & Dialkyl phosphite (equiv) & $T\left({ }^{\circ} \mathrm{C}\right)$ & \multicolumn{3}{c}{ Product composition $(\%)^{\mathrm{a}}$} \\
& & & & $\mathbf{7}$ & $\mathbf{9}$ & $\mathbf{1 0}$ & $\mathbf{1 1}$ & $\mathbf{3 c}$ \\
\hline 1 & $\mathrm{Me}$ & 2 & 110 & 14 & 36 & 36 & 11 & 3 \\
2 & $\mathrm{Me}$ & 6 & 110 & 54 & 37 & 9 & 0 & 0 \\
3 & $\mathrm{Me}$ & 10 & 110 & 77 & 18 & 5 & 0 & 0 \\
4 & $\mathrm{Me}$ & 15 & 110 & 87 & 13 & 0 & 0 & 0 \\
5 & $\mathrm{Me}$ & $20^{\mathrm{b}}$ & 110 & $\mathbf{9 1}$ & 9 & 0 & 0 & 0 \\
6 & $\mathrm{Bu}$ & 2 & 150 & 19 & 23 & 29 & 26 & 3 \\
7 & $\mathrm{Bu}$ & 6 & 125 & 54 & 33 & 10 & 3 & 0 \\
8 & $\mathrm{Bu}$ & 10 & 125 & 82 & 16 & 2 & 0 & 0 \\
9 & $\mathrm{Bu}$ & 15 & 93 & 7 & 0 & 0 & 0 \\
10 & $\mathrm{Bu}$ & 125 & 95 & 5 & 0 & 0 & 0 \\
\hline
\end{tabular}

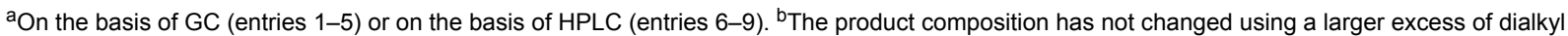
phosphite.

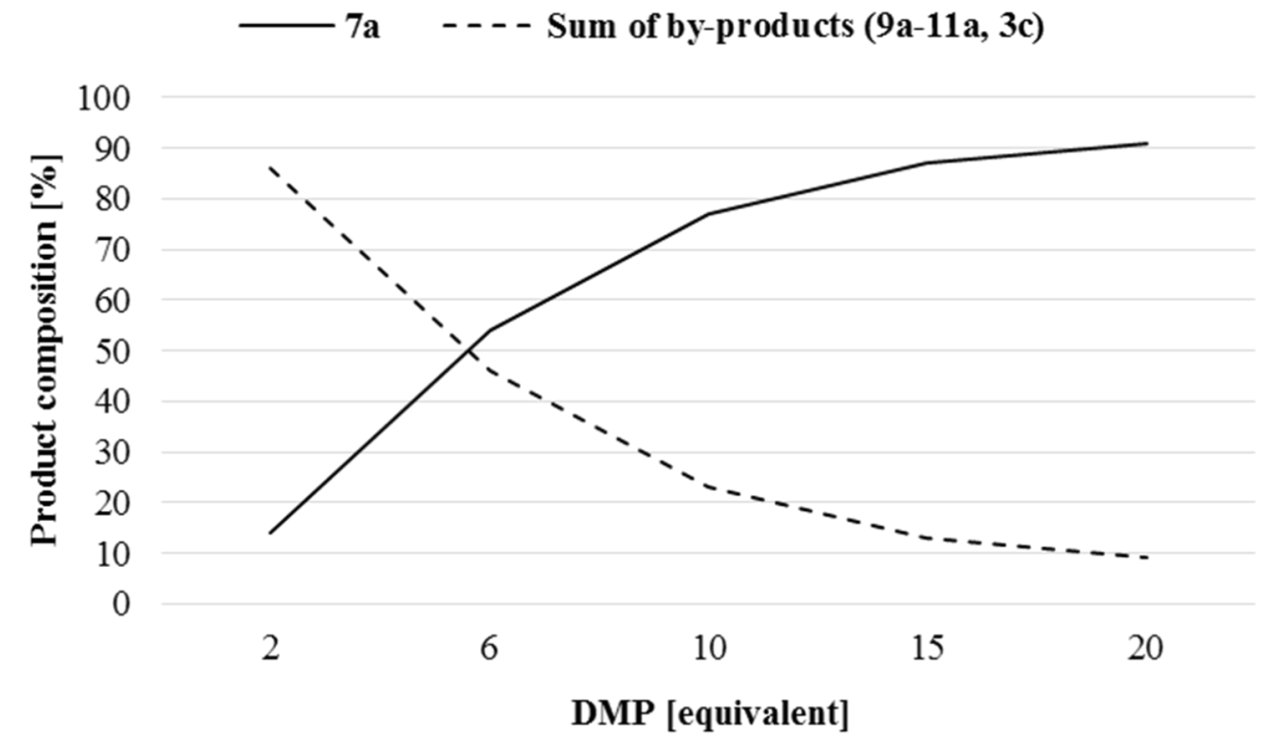

Figure 1: Effect of the quantity of dimethyl phosphite (DMP) on the product composition (from Table 6, entries 1-5.) 


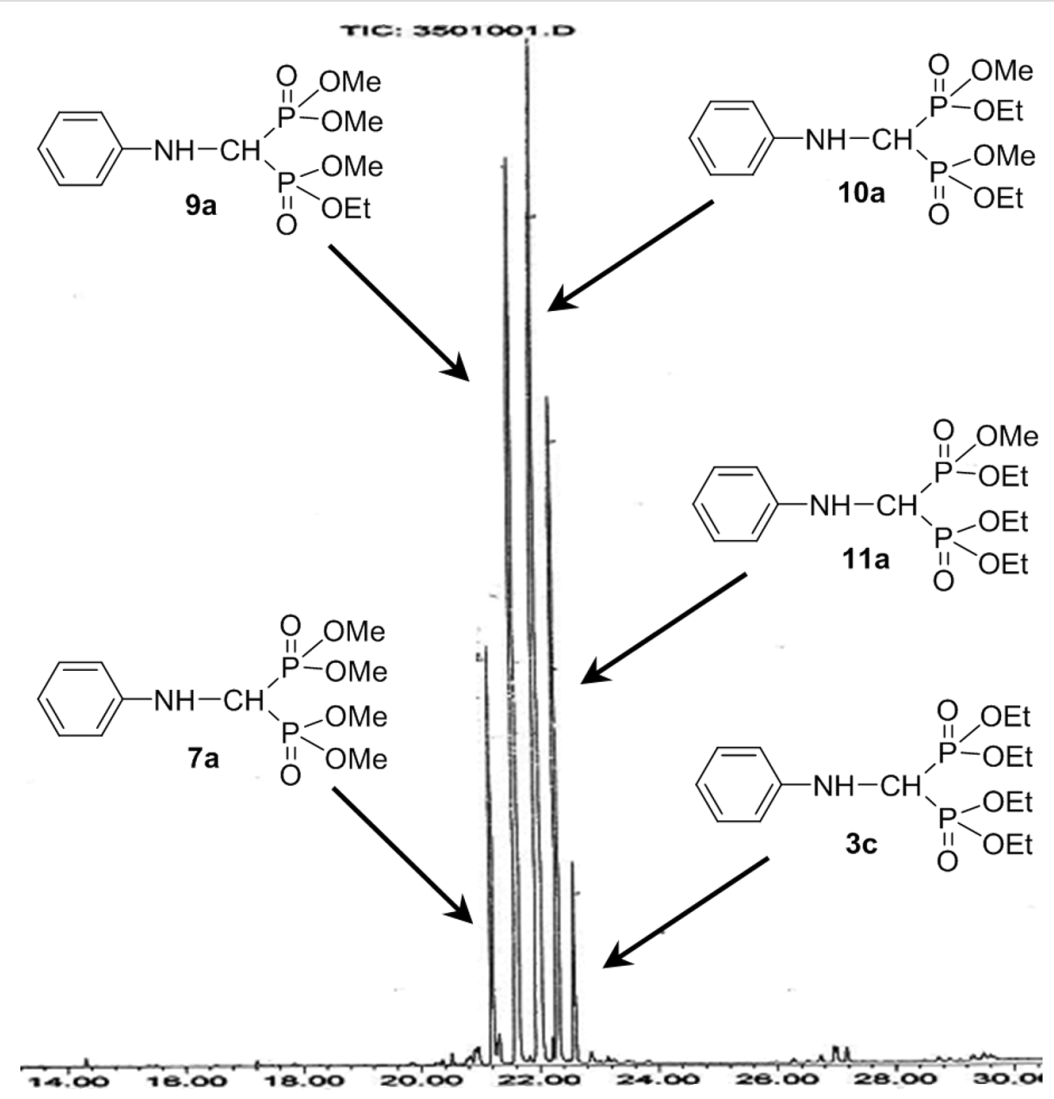

Figure 2: GC-MS chromatogram for the condensation of aniline, triethyl orthoformate and 2 equivalents of dimethyl phosphite (from the exp. marked by Table 6 , entry 1 ).
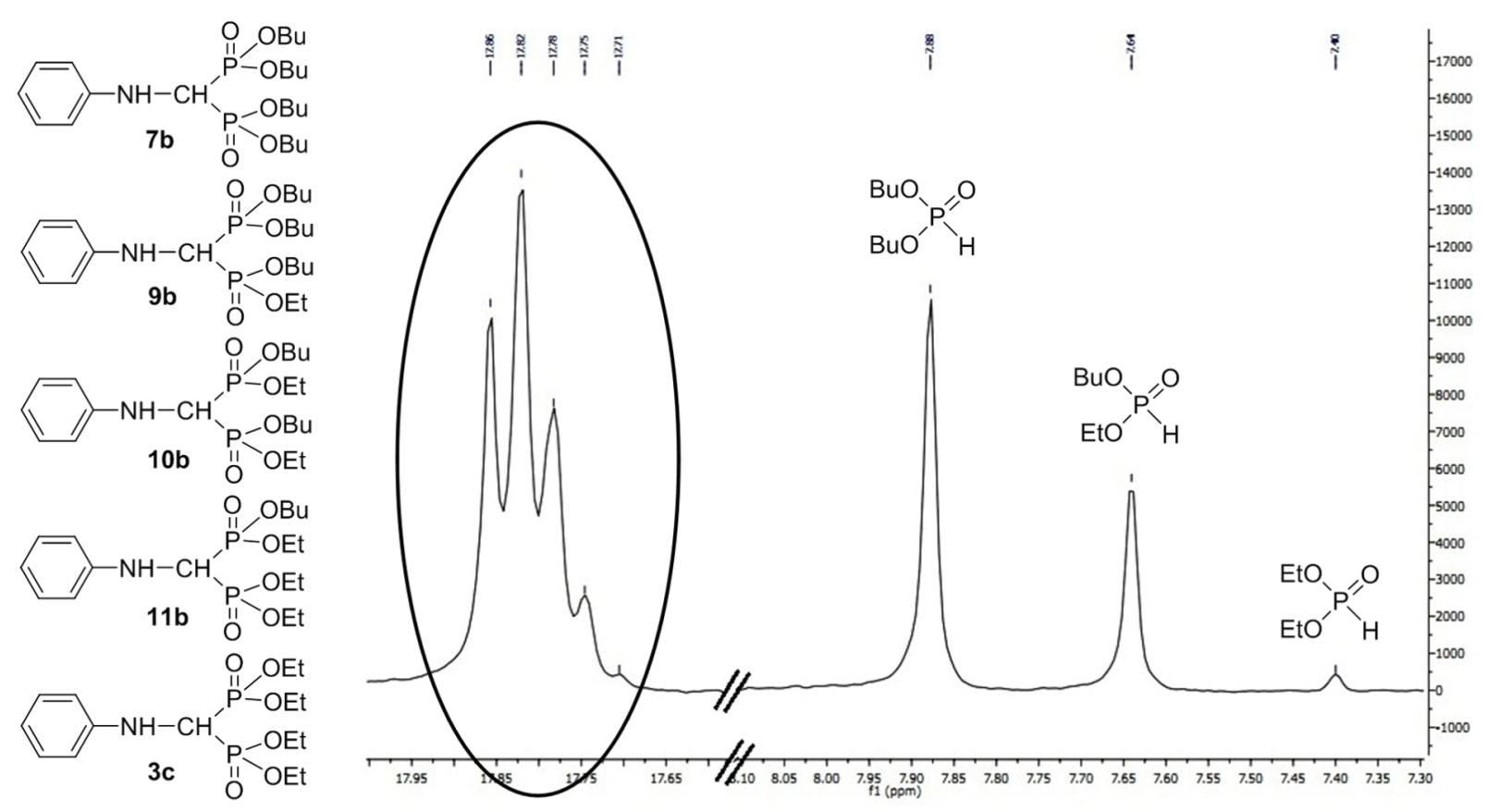

Figure 3: ${ }^{31} \mathrm{P}$ NMR spectrum for the condensation of aniline, triethyl orthoformate and 2 equivalents of dibutyl phosphite (from the exp. marked by Table 6, entry 6). 
Table 7: Mass spectral characterization of (aminomethylene)bisphosphonates.

\begin{tabular}{|c|c|c|c|c|}
\hline & \multicolumn{2}{|c|}{$\mathrm{R}=\mathrm{Me}(\mathrm{b})$} & \multicolumn{2}{|c|}{$\mathrm{R}=\mathrm{Bu}(\mathrm{c})$} \\
\hline & {$[\mathrm{M}+\mathrm{H}]_{\text {found }}^{+}$} & {$[\mathrm{M}+\mathrm{H}]^{+}$requires } & {$[\mathrm{M}+\mathrm{H}]^{+}$found } & {$[\mathrm{M}+\mathrm{H}]^{+}$requires } \\
\hline 7 & 324.0760 & 324.0760 & 492.2648 & 492.2638 \\
\hline 9 & 338.0921 & 338.0917 & 464.2329 & 464.2325 \\
\hline 10 & 352.1072 & 352.1073 & 436.2011 & 436.2012 \\
\hline 11 & 366.1231 & 366.1230 & 408.1711 & 408.1699 \\
\hline $3 c$ & 380.1382 & 380.1386 & 380.1382 & 380.1386 \\
\hline
\end{tabular}

\section{Conclusion}

In summary, we have developed a facile, solvent- and catalystfree $\mathrm{MW}$-assisted method for the synthesis of (aminomethylene)bisphosphine oxides (AMBPOs) and (aminomethylene)bisphosphonates by the condensation of a primary or secondary amine, an orthoformate, and diphenylphosphine oxide or a dialkyl phosphite. This method is a novel approach for the preparation of AMBPOs and an optimized process for the synthesis of (aminomethylene)bisphosphonates. Twentytwo derivatives were isolated and characterized, except two, all of them are new compounds. Furthermore, a few intermediates supporting the mechanism of the condensation, and several by-products were also identified.

\section{Supporting Information}

Experimental procedures, characterization data, details of the NMR structural determination of all products and copies of ${ }^{31} \mathrm{P},{ }^{1} \mathrm{H}$, and ${ }^{13} \mathrm{C}$ NMR spectra for all compounds synthesized are presented in Supporting Information File 1.

\section{Supporting Information File 1}

Experimental, NMR spectra.

[http://www.beilstein-journals.org/bjoc/content/ supplementary/1860-5397-12-146-S1.pdf]

\section{Acknowledgements}

The above project was supported by the Hungarian Scientific Research Fund (PD111895) and the Hungarian Research Development and Innovation Fund (K119202).

\section{References}

1. Breuer, E. The Development of Bisphosphonates as Drugs. In Analogue-based Drug Discovery; Fischer, J.; Ganelli, C. R., Eds.; Wiley-VCH: Weinheim, 2006; pp 371-384.

2. Russell, R. G. G. Pediatrics 2007, 119 (Suppl. 2), S150-S162. doi:10.1542/peds.2006-2023H

3. Russell, R. G. G. Bone 2011, 49, 2-19. doi:10.1016/j.bone.2011.04.022
4. Hudson, H. R.; Wardle, N. J.; Bligh, S. W. A.; Greiner, I.; Grün, A.; Keglevich, G. Mini-Rev. Med. Chem. 2012, 12, 313-325. doi:10.2174/138955712799829285

5. Romanenko, V. D.; Kukhar, V. P. ARKIVOC 2012, No. iv, 127-166. doi:10.3998/ark.5550190.0013.411

6. Krutikov, V. I.; Erkin, A. V.; Pautov, P. A.; Zolotukhina, M. M. Russ. J. Gen. Chem. 2003, 73, 187-191. doi:10.1023/A:1024775501781

7. Dąbrowska, E.; Burzyńska, A.; Mucha, A.; Matczak-Jon, E.; Sawka-Dobrowolska, W.; Berlicki, Ł.; Kafarski, P. J. Organomet. Chem. 2009, 694, 3806-3813. doi:10.1016/j.jorganchem.2009.07.025

8. Tauro, M.; Laghezza, A.; Loiodice, F.; Agamennone, M.; Campestre, C.; Tortorella, P. Bioorg. Med. Chem. 2013, 21, 6456-6465. doi:10.1016/j.bmc.2013.08.054

9. Takeuchi, M.; Sakamoto, S.; Yoshida, M.; Abe, T.; Isomura, Y. Chem. Pharm. Bull. 1993, 41, 688-693. doi:10.1248/cpb.41.688

10. Ekimoto, H. Metal Complex Compound, Cancer Therapeutic Composition Comprising the Metal Complex Compound as Active Ingredient, and Intermediate for Production of the Metal Complex Compound. Eur. Pat. EP2177525 A1, April 21, 2010.

11. Rose, Y. S.; Ciblat, S.; Kang, T.; Far, A. R.; Dietrich, E.; Lafontaine, Y.; Reddy, R. Phosphonated Rifamycins and Uses Thereof or the Prevention and Treatment of Bone and Joint Infections. U.S. Patent US20110263534 A1, Oct 27, 2011.

12. Zhang, Q. M.; Serpe, M. J. Macromolecules 2014, 47, 8018-8025. doi:10.1021/ma501997x

13. Kantoci, D.; Denike, J. K.; Wechter, W. J. Synth. Commun. 1996, 26, 2037-2043. doi:10.1080/00397919608003560

14. Kubíček, V.; Rudovský, J.; Kotek, J.; Hermann, P.; Vander Elst, L.; Muller, R. N.; Kolar, Z. I.; Wolterbeek, H. T.; Peters, J. A.; Lukeš, I. J. Am. Chem. Soc. 2005, 127, 16477-16485. doi:10.1021/ja054905u

15. Forlani, G.; Occhipinti, A.; Berlicki, Ł.; Dziedzioła, G.; Wieczorek, A.; Kafarski, P. J. Agric. Food Chem. 2008, 56, 3193-3199. doi:10.1021/jf800029t

16. Martin, M. B.; Grimley, J. S.; Lewis, J. C.; Heath, H. T., III; Bailey, B. N.; Kendrick, H.; Yardley, V.; Caldera, A.; Lira, R.; Urbina, J. A.; Moreno, S. N. J.; Docampo, R.; Croft, S. L.; Oldfield, E. J. Med. Chem. 2001, 44, 909-916. doi:10.1021/jm0002578

17. Widler, L.; Jaeggi, K. A.; Glatt, M.; Müller, K.; Bachmann, R.; Bisping, M.; Born, A.-R.; Cortesi, R.; Guiglia, G.; Jeker, H.; Klein, R.; Ramseier, U.; Schmid, J.; Schreiber, G.; Seltenmeyer, Y.; Green, J. R. J. Med. Chem. 2002, 45, 3721-3738. doi:10.1021/jm020819i

18. Forlani, G.; Berlicki, Ł.; Duò, M.; Dziędzioła, G.; Giberti, S.; Bertazzini, M.; Kafarski, P. J. Agric. Food Chem. 2013, 61, 6792-6798. doi:10.1021/jf401234s 
19. Kotsikorou, E.; Song, Y.; Chan, J. M. W.; Faelens, S.; Tovian, Z.; Broderick, E.; Bakalara, N.; Docampo, R.; Oldfield, E. J. Med. Chem. 2005, 48, 6128-6139. doi:10.1021/jm058220g

20. Parniak, M.; Mellors, J. W.; Oldfield, E.; Tovian, Z.; Chan, J. M. W. Composition and Methods for Use of Antiviral Drugs in the Treatment of Retroviral Diseases Resistant to Nucleoside Reverse Transcriptase Inhibitors. U.S. Patent Appl. US20050113331 A1, May 26, 2005.

21. Chmielewska, E.; Mazur, Z.; Kempińska, K.; Wietrzyk, J.; Piątek, A.; Kuryszko, J. J.; Kiełbowicz, Z.; Kafarski, P. Phosphorus, Sulfur Silicon Relat. Elem. 2015, 190, 2164-2172. doi:10.1080/10426507.2015.1085046

22. Fallouh, F.; Bernier, D.; Virieux, D.; Cristau, H. J.; Pirat, J. L. Phosphorus, Sulfur Silicon Relat. Elem. 2006, 181, 219-225. doi:10.1080/104265090969766

23. Leung, C.-Y.; Langille, A. M.; Mancuso, J.; Tsantrizos, Y. S. Bioorg. Med. Chem. 2013, 21, 2229-2240. doi:10.1016/j.bmc.2013.02.006

24. Reddy, M. V.; Kalla, R. M. N.; Dong, L. S.; Jeong, Y. T. Catal. Commun. 2015, 61, 102-106. doi:10.1016/j.catcom.2014.12.021

25. Kunda, U. M. R.; Balam, S. K.; Nemallapudi, B. R.; Chereddy, S. S.; Nayak, S. K.; Cirandur, S. R. Chem. Pharm. Bull. 2012, 60, 104-109. doi:10.1248/cpb.60.104

26. Reddy, M. V. N.; Kim, J.; Jeong, Y. T. J. Fluorine Chem. 2012, 135, 155-158. doi:10.1016/j.jfluchem.2011.10.005

27. Prasad, S. S.; Jayaprakash, S. H.; Syamasundar, C.; Sreelakshmi, P.; Bhuvaneswar, C.; Bhaskar, B. V.; Rajendra, W.; Nayak, S. K.; Reddy, C. S. Phosphorus, Sulfur Silicon Relat. Elem. 2015, 190 , 2040-2050. doi:10.1080/10426507.2015.1054928

28. Minaeva, L. I.; Patrikeeva, L. S.; Kabachnik, M. M.; Beletskaya, I. P.; Orlinson, B. S.; Novakov, I. A. Heteroat. Chem. 2011, 22, 55-58. doi:10.1002/hc.20656

29. Minaeva, L. I.; Kabachnik, M. M.; Ponomarev, G. V.; Morozova, J. V.; Beletskaya, I. P. Synthesis 2010, 2451-2455. doi:10.1055/s-0029-1218781

30. Reddy, G. C. S.; Reddy, M. V. N.; Reddy, N. B.; Reddy, C. S. Phosphorus, Sulfur Silicon Relat. Elem. 2010, 186, 74-80. doi:10.1080/10426507.2010.482542

31. Kaboudin, B.; Alipour, S. Tetrahedron Lett. 2009, 50, 4243-4245. doi:10.1016/j.tetlet.2009.05.016

32. Lacbay, C. M.; Mancuso, J.; Lin, Y.-S.; Bennett, N.; Götte, M.; Tsantrizos, Y. S. J. Med. Chem. 2014, 57, 7435-7449. doi:10.1021/jm501010f

33. Prishchenko, A. A.; Livantsov, M. V.; Novikova, O. P.; Livantsova, L. I.; Erschov, I. S.; Petrosyan, V. S. Heteroat. Chem. 2015, 26, 101-105. doi:10.1002/hc. 21220

34. Wang, A.-E.; Chang, Z.; Sun, W.-T.; Huang, P.-Q. Org. Lett. 2015, 17, 732-735. doi:10.1021/acs.orglett.5b00004

35. Goldeman, W.; Kluczyński, A.; Soroka, M. Tetrahedron Lett. 2012, 53, 5290-5292. doi:10.1016/j.tetlet.2012.07.085

36. Pudovik, A. N.; Nikitina, V. I.; Zimin, M. G.; Vostretsova, N. L. J. Gen. Chem. USSR 1975, 45, 1450-1455.

37. Olive, G.; Jacques, A. Phosphorus, Sulfur Silicon Relat. Elem. 2003, 178, 33-46. doi:10.1080/10426500307821

38. Lecerclé, D.; Gabillet, S.; Gomis, J.-M.; Taran, F. Tetrahedron Lett. 2008, 49, 2083-2087. doi:10.1016/j.tetlet.2008.01.127

39. Gross, H.; Costisella, B. J. Prakt. Chem. 1969, 311, 925-929. doi:10.1002/prac.19693110610

40. Morgalyuk, V. P.; Strelkova, T. V.; Nifant'ev, E. E. Bull. Chem. Soc. Jpn. 2012, 85, 93-100. doi:10.1246/bcsj.20110157
41. Morgalyuk, V. P.; Strelkova, T. V.; Nifant'ev, E. E. Russ. Chem. Bull. 2012, 61, 380-385. doi:10.1007/s11172-012-0053-2

42. Hirai, T.; Han, L.-B. J. Am. Chem. Soc. 2006, 128, 7422-7423. doi:10.1021/ja060984d

43. Costisella, B.; Gross, H. J. Prakt. Chem. 1979, 321, 361-369. doi:10.1002/prac.19793210303

\section{License and Terms}

This is an Open Access article under the terms of the Creative Commons Attribution License

(http://creativecommons.org/licenses/by/2.0), which permits unrestricted use, distribution, and reproduction in any medium, provided the original work is properly cited.

The license is subject to the Beilstein Journal of Organic Chemistry terms and conditions:

(http://www.beilstein-journals.org/bjoc)

The definitive version of this article is the electronic one which can be found at: $\underline{\text { doi: } 10.3762 / \text { bjoc. } 12.146}$ 